\title{
EL DERECHO COMPARADO COMO ARGUMENTO \\ DE LAS DECISIONES DEL TRIBUNAL CONSTITUCIONAL ESPAÑOL
}

\section{Comparative Law as an Argument in the Decisions of Spanish Constitutional Court}

\author{
PEDRO TENORIO \\ Universidad Nacional de Educación a Distancia \\ pedrojuliotenorio@gmail.com
}

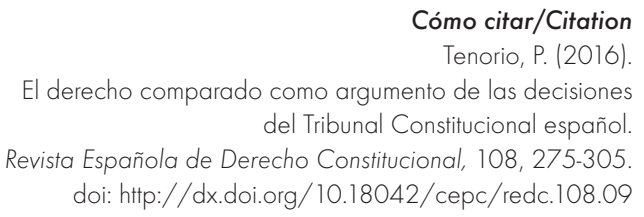

Resumen

El trabajo repasa la utilización del derecho comparado por parte del Tribunal Constitucional español desde sus primeras resoluciones, que datan de agosto de 1980, hasta la actualidad. Aunque el Tribunal lo emplea más de lo que reconoce, él mismo cita el derecho comparado en aproximadamente medio centenar de resoluciones, la mayoría de ellas relativas a casos difíciles, muy discutidos, en los que se pretende reforzar el criterio del derecho interno con el de democracias consolidadas. Ha de subrayarse la STC 12/2008, de 29 enero, en la que el Tribunal dice que la Constitución española constituye su único canon de constitucionalidad. A pesar de ello, en la propia Sentencia y en otras posteriores, el Tribunal hace consideraciones a veces muy importantes de derecho comparado.

\section{Palabras clave}

Argumentación jurídica; derecho comparado; jurisprudencia; igualdad efectiva; motivación jurídica; objeción de conciencia; paridad; ratio decidendi; sentencias; Tribunal Constitucional. 


\begin{abstract}
The paper revises the use of comparative law by the Spanish Constitutional Court from early resolutions dating back to August 1980 until today. Although the Court employs it more than it recognises, the Court quotes comparative law in about fifty resolutions, most of them relating to difficult, highly contentious issues in which it is intended to reinforce the criterion of national law with that of consolidated democracies. Specially relevant in this respect is STC 12/2008 of 29 January, in which the Court said that the Spanish Constitution is its unique canon of constitutionality. However, in the judgment itself and on other subsequent occasions, the Court raises sometimes very important considerations of comparative law .
\end{abstract}

\title{
Keywords
}

Legal argument; Comparative law; jurisprudence; effective equality; legal reasoning; conscientious objection; parity; ratio decidendi; judgements; Constitutional Court. 


\section{SUMARIO}

I. PLANTEAMIENTO. OBJETO DEL TRABAJO. II. APLICACIÓN DEL DERECHO COMPARADO POR EL TRIBUNAL CONSTITUCIONAL ESPAÑOL: 1. Sentencias en que se invocó derecho comparado antes la STC 12/2008, de 29 de enero: 1.1. Recursos de inconstitucionalidad en cuya resolución se reconoció la influencia el derecho comparado. 1.2. Cuestiones de inconstitucionalidad en cuya resolución se reconoció la influencia del derecho comparado. 1.3. Recursos de amparo en cuya resolución se reconoció la influencia del derecho comparado. 2. STC 12/2008, de 29 de enero, e igualdad de sexos en las listas electorales. El Tribunal Constitucional se plantea el empleo del derecho comparado y concluye que el único canon de sus decisiones ha de ser la Constitución española. 3. Resoluciones del Tribunal Constitucional relativas al derecho comparado posteriores a la STC 12/2008, de 29 de enero: 3.1. STC 198/2012, de 6 de noviembre: invocación de la tendencia del derecho comparado para fundamentar la constitucionalidad de la ley que estableció el matrimonio homosexual. 3.2. ATC 180/2013, de 17 de septiembre: derecho comparado para fundamentar la posibilidad de que los magistrados del Tribunal Constitucional estén vinculados a partidos políticos. 3.3. STC 199/2013, de 5 de diciembre: invocación del derecho comparado para delimitar la validez de una prueba relacionada con el ADN. 3.4. STC de Pleno 92/2014, de 10 de junio: Sentencias del Tribunal Constitucional que aplican su doctrina. III. CONCLUSIONES Y CONSIDERACIONES FINALES. BIBLIOGRAFÍA.

\section{PLANTEAMIENTO. OBJETO DEL TRABAJO}

1. En virtud del Auto 180/2013, de 17 de septiembre, nuestro Tribunal Constitucional (TC) rechazaba varias recusaciones planteadas por la Comunidad Autónoma de Cataluña contra el presidente del propio TC. El hecho que había dado lugar a las recusaciones fue el descubrimiento de que el actual presidente del TC había realizado durante un tiempo una aportación anual de 37 euros a un partido político, de lo que un periódico deducía su afiliación a este y presentaba el hecho como una ilegalidad.

En realidad, se trata de una conducta impecablemente legal. El art. 159.4 de nuestra Constitución (CE) establece que la condición de miembro del TC es incompatible, entre otras actividades, con el desempeño de funciones directivas en un partido político o en un sindicato y con el empleo al servicio de los mismos. Idéntica redacción presenta el art. 19.1 de la Ley Orgánica del Tribunal Constitucional (LOTC). Nótese que se refiere solo a las funciones directivas y a tener empleo al servicio de un partido político. 
Por el contrario, el art. 127 CE prohíbe a los jueces integrantes del poder judicial la militancia en partidos políticos y sindicatos. Es una diferencia que el constituyente ha querido establecer conscientemente.

Sin embargo, a pesar de la claridad que presentaba la cuestión ${ }^{1}$ desde el punto de vista del derecho interno, el Auto argumentaba ampliamente, como veremos, con razones de derecho comparado.

2. En el presente trabajo pretendemos analizar de modo principal el empleo del derecho comparado por nuestro TC realizando un examen que pretende ser exhaustivo de las resoluciones en que se cita expresamente el derecho comparado o alguna resolución de determinado Tribunal Constitucional extranjero.

3. En derecho constitucional es imprescindible el uso del derecho comparado (Torres del Moral, 2010: 125). En este trabajo estudiamos su empleo por nuestro TC. Se usa judicialmente el derecho comparado cuando el tribunal, para resolver un supuesto que se le plantea, aplica la regulación o la jurisprudencia acerca de supuestos similares en otro país u otros países, pretendiendo deducir de ello una regla generalizada en países que tienen ordenamientos prestigiosos. Ahora bien, del análisis del diálogo entre tribunales y de otras formas de influencia entre tribunales extrae el profesor De Vergottini (2010: 209) algunas consideraciones de orden sistemático útiles para fijar ulteriores criterios metodológicos para ser utilizados en la comparación en el ámbito del derecho constitucional.

a) Señala ante todo que ha de insistirse en la línea de delimitación entre simples referencias a experiencias de otros países y comparación.

b) En segundo lugar, ha de observarse que la posibilidad de practicar en concreto la comparación por parte de los tribunales resulta realmente limitada a los casos en que se pueda verificar la presencia de valores comunes compartidos.

c) Ha de tenerse presente que, en general, se confirma el principio del carácter completo y de la autosuficiencia del ordenamiento estatal. Al respecto, es de recordar la explícita declaración de nuestro TC que ha afirmado con claridad que el único canon constitucional a seguir es la Constitución estatal ${ }^{2}$.

d) Esto sentado, es posible indicar una gradación de las tendencias manifestadas por los tribunales respecto del recurso al derecho extranjero y a la

Vid. ATC 226/1988.

2 Cfr. STC 12/2008, de 29 de enero: «la Constitución española, [...] constituye, obviamente, nuestro único canon de constitucionalidad». 
comparación. Siguiendo a De Vergottini $(2010,210)$, cabe distinguir: 1) jueces que rechazan el recurso a fuentes externas al ordenamiento (como el magistrado del Tribunal Supremo de Estados Unidos Scalia); 2) jueces que conocen el derecho externo, pero no lo citan en sus pronunciamientos; sería el caso, según algunos (Carpentier, 2009: 475), del Conseil Constitutionnel francés; 3) jueces que simplemente mencionan el derecho externo, en un ejercicio de erudición discursiva ${ }^{3}$; 4) jueces que utilizan de manera pertinente el derecho extranjero y la comparación.

4. Como requisitos para poder calificar una invocación de derecho comparado en sentido propio, cabe señalar:

a) Hace falta distinguir de la comparación que incide en la ratio decidendi la cita que puede ser efectuada del derecho y de la jurisprudencia en los antecedentes de Hecho de una sentencia. Por tanto, debe considerarse si la cita aparece en los fundamentos jurídicos (FFJJ) de la sentencia y ha de valorarse su incidencia en el fallo.

b) Hace falta que exista la tendencial posibilidad de acceder a la cita del derecho distinto del nacional.

Con estos criterios, para el profesor De Vergottini, existen pocos casos en que el juez procede en sentido propio a la comparación entre diversas contribuciones jurisprudenciales, como también entre diversas regulaciones constitucionales. Sería lo sucedido en la experiencia de Canadá, Australia o Sudáfrica. Probablemente deba añadirse la utilización de la jurisprudencia del Tribunal Constitucional Federal alemán acerca de la dignidad humana por parte del Tribunal Constitucional húngaro.

Desde el punto de vista científico, la postura del profesor De Vergottini es inobjetable. Sin embargo, habiendo trabajado dentro de nuestro TC, se siente uno proclive a matizarla señalando que los casos en que el TC español hace referencia al derecho comparado constituyen solamente la punta de un iceberg, como se ha dicho con referencia al Tribunal de Justicia de la Unión Europea (TJUE) (Mertens de Wilmars, 1991: 37). Es decir: el derecho comparado se usa en ocasiones sin citarse en las sentencias o sin reflejar en las mismas toda la relevancia que ha tenido. Con ello, no obstante, no pretendemos decir que se use el derecho comparado por el TC español tanto como por el TJUE, un ámbito en el cual tal derecho llega a tener la naturaleza de fuente,

3 Esto sería lo que habría hecho, según el Profesor De Vergottini, el Tribunal Constitucional español en la STC 136/1999, de 20 de julio. 
no de argumento para la interpretación del derecho interno, como es el caso entre nosotros.

\section{APLICACIÓN DEL DERECHO COMPARADO POR EL TRIBUNAL CONSTITUCIONAL ESPAÑOL}

El derecho comparado es invocado ante nuestro TC. Repasando las resoluciones dictadas por este, encontramos que, desde $1980^{4}$ hasta 31 de julio de $2016^{5}$, el derecho comparado ha sido invocado ante el mismo al menos en 85 ocasiones $^{6}$.

4 El primer auto que dictó el TC fue el ATC 1/1980, de 11 de agosto. La primera sentencia, la STC 1/1981, de 26 de enero.

5 Se cierra este trabajo en julio de 2016.

6 Son los casos en que ha quedado rastro en los antecedentes de Hecho de la Sentencia, mencionándose expresamente el «derecho comparado». Sentencias (SSTC) 26/1981, de 17 de julio; 12/1982, de 31 de marzo; 15/1982, de 23 de abril; 24/1982, de 13 de mayo; 36/1982, de 16 de junio; 47/1982, de 12 de julio; 57/1982, de 27 de julio; 67/1982, de 15 de noviembre; 68/1982, de 22 de noviembre; 101/1983, de 18 de noviembre; 111/1983, de 2 de diciembre; 16/1984, de 6 de febrero; 44/1984, de 27 de marzo; 72/1984, de 14 de junio; 83/1984, de 24 de julio; 53/1985, de 11 de abril; 55/1985, de 22 de abril; 98/1985, de 29 de julio; 45/1986, de 17 de abril; 88/1986, de 1 de julio; 99/1986, de 11 de julio; 108/1986, de 29 de julio; 137/1986, de 6 de noviembre; 152/1986, de 4 de diciembre; 19/1987, de 17 de febrero; 89/1987, de 3 de junio; 19/1988, de 16 de febrero; 118/1988, de 20 de junio; 209/1988, de 10 de noviembre; 14/1989, de 26 de enero; 45/1989, de 20 de febrero; 72/1989, de 20 de abril; 89/1989, de 11 de mayo; 137/1989, de 20 de julio; 178/1989, de 2 de noviembre; 193/1989, de 16 de noviembre; 214/1989, de 21 de diciembre; 41/1990, de 15 de marzo; 76/1990, de 26 de abril; 119/1990, de 21 de junio; 205/1990, de 13 de diciembre; 211/1990, de 20 de diciembre; 45/1991, de 28 de febrero; 46/1991, de 28 de febrero; 150/1991, de 4 de julio; 14/1992, de 10 de febrero; 107/1992, de 1 de julio; 222/1992, de 11 de diciembre; 227/1993, de 9 de julio; 254/1993, de 20 de julio; 37/1994, de 10 de febrero; 165/1994, de 26 de mayo; 218/1994, de 18 de julio; 337/1994, de 23 de diciembre; 7/1996, de 18 de enero; 196/1997, de 13 de noviembre; 206/1997, de 27 de noviembre; 14/1998, de 22 de enero; 103/1999, de 3 de junio; 98/2000, de 10 de abril; 102/2000, de 10 de abril; 188/2000, de 10 de julio; 290/2000, de 30 de noviembre; 29/2004, de 4 de marzo; 179/2004, de 21 de octubre; 237/2005, de 26 de septiembre; 235/2007, de 7 de noviembre; 12/2008, de 29 de enero; 59/2008, de 14 de mayo; 83/2008, de 17 de julio; 98/2009, de 27 de abril; $137 / 2010$, de 16 de diciembre; 20/2012, de 16 de febrero; 198/2012, de 6 de noviembre; 114/2013, de 9 de mayo; 82/2016, de 28 de abril; 46/2015, de 5 de marzo; 
En los FFJJ de sentencias o autos, fue mencionado en 51 ocasiones ${ }^{7}$.

El derecho comparado se aplica tanto en recursos de inconstitucionali$\operatorname{dad}^{8}$ como en cuestiones de inconstitucionalidad ${ }^{9}$ y recursos de amparo ${ }^{10}$.

Estudiando este acervo jurisprudencial y escogiendo los casos en que el uso del derecho comparado es más relevante desde la perspectiva de la ratio decidendi, vamos a ofrecer a continuación un análisis de la jurisprudencia del Tribunal Constitucional español ordenado conforme a los criterios que puntualizamos seguidamente. Ante todo, vamos a referirnos al uso del dere-

15/2015, de 5 de febrero; 197/2014, de 4 de diciembre; 153/2014, de 25 de septiembre; 119/2014, de 16 de julio; AATC 120/1983, de 21 de marzo de 1983; 351/1989, de 19 de junio de 1989; 178/1996, de 26 de junio de 1996; 505/2005, de 13 de diciembre.

7 AATC 12/1986, de 15 de enero de 1986; 171/1986, de 19 de febrero de 1986; 180/1986, de 21 de febrero de 1986; 496/1989, de 16 de octubre de 1989; 174/1995, de 6 de junio de 1995; 349/1995, de 19 de diciembre de 1995; 350/1995, de 19 de diciembre de 1995; 178/1996, de 26 de junio de 1996; 349/2003 de 29 de octubre de 2003. SSTC 4/1981 de 2 de febrero de 1981; 57/1982, de 27 de julio de 1982; 72/1984, de 14 de junio de 1984; 114/1984, de 29 de noviembre de 1984; 124/1984, de 18 de diciembre de 1984; 75/1985, de 21 de junio de 1985; 94/1985, de 29 de julio de 1985; 160/1987, de 27 de octubre de 1987; 64/1988, de 12 de abril de 1988; 45/1989, de 20 de febrero de 1989; 76/1989, de 27 de abril de 1989; 137/1989, de 20 de julio de 1989; 193/1989, de 16 de noviembre de 1989; 56/1990, de 29 de marzo de 1990; 119/1990, de 21 de junio de 1990; 150/1990, de 4 de octubre de 1990; 184/1990, de 15 de noviembre de 1990; 211/1990, de 20 de diciembre de 1990; 60/1991, de 14 de marzo de 1991; 71/1994, de 3 de marzo de 1994; 196/1997, de 13 de noviembre de 1997; 206/1997, de 27 de noviembre de 1997; 225/1998, de 25 de noviembre de 1998; 136/1999, de 20 de julio de 1999; 102/2000, de 10 de abril de 2000; 105/2000, de 13 de abril de 2000; 192/2000, de 13 de julio de 2000; /2003, de 16 de enero de 2003; 48/2003, de 12 de marzo de 2003; 123/2004, de 13 de julio de 2004; 112/2006, de 5 de abril de 2006; 12/2008, de 29 de enero de 2008; 199/2013, de 5 de diciembre de 2013; 92/2014, de 10 de junio de 2014; 93/2014, de 12 de junio de 2014; 98/2014, de 23 de junio de 2014; 115/2014, de 8 de julio de 2014; 116/2014, de 8 de julio de 2014; 124/2014, de 21 de julio de 2014.

8 SSTTCC 160/1987, de 27 de octubre; 150/1990, de 4 de octubre; 211/1990, de 20 de diciembre; 225/1998, de 25 de noviembre; 48/2003, de 12 de marzo; 198/2012, de 6 de noviembre.

$945 / 1989$, de 20 de febrero; 184/1990, de 15 de noviembre; 60/1991, de 14 de marzo; $12 / 2008$, de 29 de enero.

10 SSTTCC 15/1982, de 23 de abril; 124/1984, de 18 de diciembre; 64/1988, de 12 de abril; 136/1999, de 20 de julio; 123/2004, de 13 de julio. 
cho comparado antes de la importante STC 12/2008, en la que el TC se pronuncia explícitamente acerca de la cuestión. Esta parte recoge un número considerable de sentencias que hemos ordenado subdistinguiendo las pronunciadas en el marco de diferentes competencias del TC: recursos de inconstitucionalidad, cuestiones de inconstitucionalidad y recursos de amparo. En segundo lugar, analizamos la STC 12/2008. En tercer lugar, nos referiremos a la jurisprudencia sobre el tema posterior a la STC 12/2008. Dentro de los apartados primero y tercero ordenamos las sentencias cronológicamente.

Probablemente, durante los primeros años de funcionamiento del TC, este no tuvo más remedio que inspirarse en los ejemplos italiano y alemán. Pero el caso es que, hasta donde hemos alcanzado a ver, de aquello no ha quedado ninguna constancia en las sentencias que nos permita distinguir diferentes fases. Los períodos que aquí establecemos se basan en la observación de los casos en los que el derecho comparado se cita expresamente.

\section{SENTENCIAS EN QUE SE INVOCÓ DERECHO COMPARADO ANTES LA STC 12/2008, DE 29 DE ENERO}

Con anterioridad a la STC 12/2008, nuestro TC hizo alusiones al derecho comparado sin cuestionarse hasta qué punto este puede ser empleado por él, bien como un argumento inserto en la ratio decidendi, bien como un argumento a mayor abundamiento. Este uso del derecho comparado se produjo en las competencias más destacadas de TC: recursos de inconstitucionalidad, cuestiones de inconstitucionalidad y recursos de amparo.

\subsection{Recursos de inconstitucionalidad en cuya resolución se reconoció la influencia el derecho comparado}

1.1.1. STC 25/1981, de 14 de julio: invocación del derecho comparado para fundamentar la conexión del Estado de derecho con el reconocimiento y garantía de los derechos fundamentales

La STC 25/1981, de 14 de julio, denegó al Parlamento vasco legitimación para impugnar ante el TC la Ley Orgánica (LO) 11/80, sobre los supuestos de suspensión de los derechos previstos en el art. 55.2 de nuestra CE.

En aquella Sentencia se recogió la doctrina del doble carácter que tienen los derechos fundamentales: como derechos subjetivos, y como elementos objetivos y esenciales del ordenamiento jurídico si este es el de un Estado de 
derecho. Y se dice que esta doble naturaleza de los derechos fundamentales se recoge en el art. 10.1 de la CE y que se encuentran afirmaciones parecidas en el derecho comparado.

La Sentencia tuvo un voto particular discrepante formulado por cuatro magistrados.

\subsubsection{STC 53/1985, de 11 de abril: derecho comparado y tratamiento del aborto}

El objeto del recurso decidido por aquella Sentencia era determinar la constitucionalidad o inconstitucionalidad del proyecto de LO que introducía el art. 417 bis en el Código Penal, por el que se declaraba no punible el aborto en determinados supuestos.

Es, como se sabe, caso típicamente difícil, en el que hubo cinco votos particulares.

En los antecedentes se narra que los recurrentes invocaron el derecho comparado para fundamentar la interpretación del art. 15 CE (derecho a la vida) en el sentido de que el término todos incluye y protege al «concebido y no nacido»; además, analizaron el derecho penal alemán y la Sentencia del Tribunal Constitucional federal de 25 de febrero de 1975 y concluyeron que los supuestos que en aquella quedan cubiertos por la no exigibilidad de otra conducta, quedan cubiertos en nuestro derecho a través de la eximente de estado de necesidad, ya que esta se perfila aquí con una extensión desconocida en el derecho comparado.

No se hace referencia explícita al derecho comparado en los FFJJ de la Sentencia, pero se percibe la influencia de la forma de proceder del Tribunal Constitucional federal alemán en la del español ${ }^{11}$.

11 La STC 160/1987, de 27 de octubre desestimó un recurso de inconstitucionalidad interpuesto por el Defensor del Pueblo contra dos leyes relacionadas con la objeción de conciencia y la prestación social sustitutoria del servicio militar. El Defensor del Pueblo había invocado el derecho comparado y así lo hizo también el TC, aunque sin abundar en detalles, y no solamente para justificar la duración de la prestación sustitutoria, sino para justificar que la protección mediante recurso de amparo no es un rasgo consustancial a los derechos fundamentales (FJ 5, C).

Fue un caso "difícil», como acredita el hecho de que tuviera tres votos particulares, ninguno de los cuales discrepa de la utilización del derecho comparado (uno la confirma, implícitamente, sin hacerse cuestión). 


\subsubsection{STC 127/1994, de 5 de mayo: invocación del criterio del Tribunal} Supremo de Estados Unidos para valorar el significado de una concesión de radio o televisión

Muestra cómo el Tribunal tiene presente el derecho comparado en los casos "difíciles» ${ }^{12}$, por más que la cita no sea absolutamente esencial en la motivación y resulte además muy concreta. Es más, llama la atención la referencia sin considerar las diferencias del modelo estadounidense, alemán y español.

Se trataba de cuatro recursos de inconstitucionalidad promovidos contra la Ley 10/1988, de Televisión Privada. Entre los reproches de inconstitucionalidad, destacaremos que se estimaba incompatible con las libertades la consideración de la televisión como un servicio público esencial de titularidad estatal que se ejercita mediante la gestión indirecta por las sociedades anónimas que hayan obtenido una concesión.

Los recursos fueron desestimados.

La Sentencia rechaza el reproche referido en un extenso Fundamento Jurídico (FJ) 6, con una abundante argumentación de derecho interno y de jurisprudencia del Tribunal Europeo de derechos Humanos (TEDH) y en uno de sus apartados, para fundamentar el régimen peculiar, se alude a sentencias del Tribunal Supremo de Estados Unidos y a una Sentencia del Tribunal Constitucional Alemán de 4 de noviembre de 1986 (BVerfGE 73, 118) que enjuició la Ley de Baja Sajonia.

La Sentencia tuvo cuatro votos particulares que no hicieron referencia de derecho comparado ni observaciones respecto de su empleo.

1.1.4. STC $225 / 1998$, de 25 de noviembre: derecho comparado aludido en relación con el establecimiento de barrera electoral

Se trataba del recurso de inconstitucionalidad, promovido por el Defensor del Pueblo, que se dirigía contra la Disposición transitoria primera de la LO 4/1996, de 30 de diciembre, de reforma del Estatuto de Autonomía de

12 El derecho comparado se usa también en casos menos importantes que no recogemos para no hacer farragosa la enumeración. Así, por ejemplo, en la STC 150/1990, de 4 de octubre, se emplea el derecho comparado para sostener que la vinculación a determinados fines de fondos transferidos a corporaciones locales no vulneraría la autonomía local; en la STC 211/1990, de 20 de diciembre, se alude al derecho comparado para fijar el concepto de denominación de origen. 
Canarias, que establecía una barrera electoral del $6 \%$. No queda en los antecedentes rastro de cita alguna de derecho comparado.

El recurso fue desestimado. Hubo un solo voto particular, que fue concurrente y que no hablaba de derecho comparado. No se puede calificar el caso de muy difícil, pero sí la materia, en particular en nuestro país. Veamos.

La cuestión de las barreras electorales es delicada. En España, en el ámbito político, hay quien propone establecerla para desalojar del Congreso de los Diputados a nacionalistas catalanes y vascos.

La barrera electoral, en el caso al que ahora nos referimos, parecía no plantear muchas dudas de inconstitucionalidad, porque existían ya otras en otras comunidades autónomas cuya constitucionalidad había sido aceptada por el TC.

Resulta interesante señalar que, para la aceptación de tales barreras, se había esgrimido el derecho comparado, como consta en la presente Senten$\mathrm{cia}^{13}$. En el caso de que se planteara en España una barrera electoral de ámbito nacional, es incuestionable que el caso alemán podría ejercer notable influencia. Por eso seleccionamos esta sentencia, aunque no se puede afirmar que en ella, en sí misma considerada, sea ratio decidendi el derecho comparado.

\subsubsection{STC $48 / 2003$, de 12 de marzo: invocación del derecho comparado para fundamentar el carácter genérico de algún tipo penal antiterrorista}

Se trataba del recurso de inconstitucionalidad interpuesto por el Gobierno Vasco impugnando, entre otros preceptos, el art. 9 de la Ley Orgánica de Partidos Políticos, LO 6/2002, de 27 de junio, de partidos políticos (LOPP), que recoge las conductas que darán lugar a la ilegalización.

No quedó en los antecedentes de Hecho rastro de invocación del derecho comparado. Aunque no hubo votos particulares, el caso puede considerarse difícil por poder suponer un grave desprestigio para nuestra democracia.

La invocación del derecho comparado va a producirse para responder al reproche de falta de proporcionalidad y de previsibilidad. El reparo encontró eco en el TC, que salvó la constitucionalidad de los apartados f) ${ }^{14}$ y g $)^{15}$ del art. 9 mediante una «interpretación conforme».

13 En el FJ 5 se cita la STC 193/1989, y se señala que esta tuvo en cuenta que barreras similares no son infrecuentes en el derecho comparado.

14 «) Colaborar habitualmente con entidades o grupos que actúan de forma sistemática de acuerdo con una organización terrorista o violenta, o que amparan o apoyan al terrorismo o a los terroristas."

15 «g) Apoyar desde las instituciones en las que se gobierna, con medidas administrativas, económicas o de cualquier otro orden, a las entidades mencionadas en el párrafo anterior.» 
Pero el TC añadió que una cierta inconcreción es inevitable en materia antiterrorista y para justificar esto invocó genéricamente el derecho comparado. Esto lo hace citando una Sentencia propia que ya argumentó de este modo: STC 136/1999, de 20 de julio. Ciertamente, no se trata del núcleo de la ratio decidendi ni de una invocación precisa y, por tanto, verificable del derecho comparado, pero nos parece una invocación relevante. Solo como colofón de la interpretación conforme y la invocación al derecho comparado se desestimó el recurso en este punto ${ }^{16}$.

\subsection{Cuestiones de inconstitucionalidad en cuya resolución se reconoció la influencia del derecho comparado}

\subsubsection{SSTC que invocan derecho comparado en el ámbito del derecho tributario}

Es importante hacer referencia, aunque sea sucinta, a dos sentencias relacionadas con el derecho tributario.

En la STC 126/1987, de 16 de julio, el TC empleó criterios de los tribunales constitucionales italiano y alemán y del Tribunal Supremo de Estados

16 En la STC 155/2005, de 9 de junio, nuestro TC consideró que ni el decreto-ley ni la ley ordinaria son idóneos para la ratificación de convenios internacionales. El magistrado Rodríguez-Zapata hizo un voto particular discrepante en el que señaló, entre otras cuestiones, que la Sentencia de la mayoría del Tribunal prohibía «uno de los contenidos típicos de la Ley en todos los ordenamientos».

En la STC 247/2007, de 12 de diciembre de 2007 con motivo de la resolución de un recurso de inconstitucionalidad interpuesto por el gobierno de la Comunidad Autónoma de Aragón contra la reforma del Estatuto de Autonomía de la Comunidad Valenciana, el Tribunal Constitucional procedió a reelaborar considerablemente su doctrina acerca de nuestro estado autonómico.

El magistrado Rodríguez-Zapata formuló un voto particular discrepante en el que llegó a calificar la Sentencia de la mayoría del Tribunal como una deconstrucción de la Constitución y un overruling respecto de la doctrina sentada en la STC 76/1983, de 5 de agosto, respecto de la LO de armonización del proceso autonómico, que desautorizó que la labor interpretativa de la Constitución llegara a suplir al constituyente. En su brillante voto particular el magistrado discrepante citaba a un presidente del Tribunal Supremo Norteamericano y al presidente del Tribunal Constitucional húngaro. A lo largo del voto particular se refiere a otros estados descentralizados como Italia, la República Federal Alemana, Suiza o Estados Unidos. Con una singular atención a lo dispuesto en la Ley Fundamental de Bonn. 
Unidos para decidir si una norma tributaria retroactiva era constitucional o no. Se trataba de varias cuestiones de inconstitucionalidad que entendían que una norma introducida en la Ley de acompañamiento a los Presupuestos Generales del Estado por la que se creó un gravamen complementario de la tasa fiscal que gravaba los juegos de suerte, envite o azar, era inconstitucional, entre otras razones, por ser retroactiva y por vulnerar el principio de seguridad jurídica.

Las cuestiones de inconstitucionalidad fueron desestimadas, y el derecho comparado desempeñó un papel importante en la argumentación. Concretamente, se trajo a colación la doctrina del Tribunal Constitucional italiano conforme a la cual una norma tributaria retroactiva resulta constitucionalmente ilegítima si vulnera el principio de capacidad contributiva y se viene a aceptar, aunque sea a efectos dialécticos, para afirmar a continuación que desde esta perspectiva no cabía apreciar una tacha de inconstitucionalidad en el precepto cuestionado. En cuanto al principio de seguridad jurídica, se trae a colación las doctrinas del Tribunal Constitucional alemán y del Tribunal Supremo de Estados Unidos, explicándola en lo sustancial en su fundamento y contenido y se puede considerar importante en la argumentación relativa a la constitucionalidad desde la perspectiva de la seguridad jurídica.

También la STC 45/1989, de 20 de febrero, muestra la importancia de la comparación en el sistema tributario. Para explicarla hemos de partir de la STC 209/1988, de 10 de noviembre, en la que el Pleno del Tribunal; a) había concedido el amparo solicitado frente a Sentencia de la Audiencia Territorial de Barcelona que había estimado correcta la imposición por la Inspección al recurrente y a su cónyuge de la acumulación de sus rentas en la declaración correspondiente a determinado ejercicio; b) había reconocido al recurrente el derecho a no ser discriminado fiscalmente por el hecho de haber contraído matrimonio y a hacer por separado su declaración del Impuesto sobre la Renta de las Personas Físicas del ejercicio en cuestión y c) había sometido al Pleno la cuestión de inconstitucionalidad de los preceptos legales en que se había fundado la actuación de la Inspección y su confirmación por la Audiencia Territorial.

Esta STC 45/1989, de 20 de febrero, resuelve la autocuestión de inconstitucionalidad así planteada.

En los antecedentes se hace referencia a un informe de la Secretaría General de Hacienda, que acompañó al escrito del abogado del Estado, que aporta datos relativos a los puntos controvertidos en la legislación española, incluyendo el derecho comparado, con el objeto de mostrar que algunas críticas dirigidas al legislador español no estaban justificadas y que en la materia 
hay que preservar un amplio margen de actuación al legislador democrático, pero no se concretan esos aspectos.

No era un caso difícil, en el sentido que venimos dando al término (sí en el sentido de requerir conocimientos de derecho fiscal para su comprensión). No hubo votos particulares.

El TC, en el fallo, declaró la inconstitucionalidad, por diferentes motivos, de cinco preceptos legales.

En la fundamentación jurídica se hace uso del derecho comparado, pero sin concretar preceptos o países, sino remitiendo al Informe de la Secretaría de Hacienda. Concretamente, el TC se remite al derecho comparado para avalar que es contrario a la $\mathrm{CE}$ el hecho de que la tributación per cápita de los cónyuges exceda de la que les correspondería de no haber contraído matrimonio.

En suma, existió un estudio científico del derecho comparado que se citó como parte del hilo argumental de la ratio decidendi, pero la Sentencia invocó el derecho comparado, sin detallar países y normas. Se emplea como punto de referencia para reforzar la legitimidad del sistema tributario. No parece que se pueda minimizar su importancia, aunque es de lamentar que no se hicieran algo más explícitas las razones de derecho comparado.

\subsubsection{STC 184/1990, de 15 de noviembre: tratamiento} de las parejas de hecho

En lo que aquí interesa, se trató de una cuestión de inconstitucionalidad promovida en relación con determinado precepto legal por exigir la condición de viuda (o viudo, de conformidad con la jurisprudencia constitucional) del cónyuge causante para tener derecho a la pensión de viudedad.

No quedó rastro de invocación de derecho comparado en los antecedentes de hecho. Era un caso dificil, pues en esta materia, con el tiempo, la jurisprudencia constitucional, que en este caso se mantuvo dentro de las coordenadas del texto, acabaría desbordando las previsiones constitucionales (Tenorio, 2013: 97). Hubo un voto particular, que no incide en el uso del derecho comparado.

Remitiéndose a anteriores resoluciones de inadmisión de demandas de amparo, el TC repite que «el matrimonio y la convivencia extramatrimonial no son situaciones equivalentes, siendo posible, por ello, que el legislador, dentro de su amplísima libertad de decisión, deduzca razonablemente consecuencias de la diferente situación de partida[...]», y ello también respecto de las pensiones de viudedad, precisando a este propósito que la actual regulación de tales pensiones no vulnera «el principio de igualdad». 
La Sentencia en su argumentación cita también el derecho internacional y derecho comparado, aunque no hace una mención concreta de países y leyes. La cita es importante en la estructura argumental de la Sentencia (FFJJ 4 y 5).

1.2.3. STC 60/1991, de 14 de marzo: atribución a la jurisdicción castrense del delito de negativa a la prestación del servicio militar

Un juez togado militar cuestionó en este proceso la constitucionalidad de la atribución a la jurisdicción militar, en situación de normalidad constitucional, del conocimiento del delito de negativa a la prestación del servicio militar ${ }^{17}$ por posible contradicción con lo previsto en el art. 117.5 CE, y en conexión con este, con el derecho al juez ordinario predeterminado por la Ley (art. 24.2 CE).

En los antecedentes no queda referencia alguna al derecho comparado.

Un caso algo difícil si tenemos en cuenta que históricamente el deslinde de lo civil y lo militar y el sometimiento de la autoridad militar a la civil han sido difíciles concretamente en España. Hubo un voto particular.

La cuestión de inconstitucionalidad es desestimada. La fundamentación de la Sentencia se centra resueltamente en la interpretación del art. 117.5 CE, pero se añade que la exégesis que se adopta es concorde con la generalidad de los sistemas comparados próximos. No es la ratio decidendi, pero tiene su importancia. No se concretan países ni leyes.

\subsection{Recursos de amparo en cuya resolución se reconoció la influencia del derecho comparado}

\subsubsection{STC 15/1982, de 23 de abril: derecho comparado influye como presupuesto para reconocer el derecho a la objeción de conciencia}

Se trataba de un recurso de amparo promovido contra acuerdo de la Junta de Clasificación y Revisión Jurisdiccional de la Zona Marítima del Estrecho en la que se denegaba la prórroga de incorporación al servicio militar solicitada alegando objeción de conciencia «por motivos personales y éticos».

El demandante solicitaba el amparo apoyándose, entre otros argumentos, en que el reconocimiento de la objeción de conciencia no circunscrito a

17 Previsto en el art. 127 del Código Penal Militar (LO 13/1985, de 9 de diciembre). 
motivaciones de carácter religioso aparece avalado por la doctrina y el derecho comparado, sin que los antecedentes detallaran este último.

No se presentó difícil, al menos, no hubo votos particulares.

El TC estimó parcialmente el recurso de amparo y reconoció el derecho del recurrente a que se aplazara su incorporación a filas hasta que se dictara la Ley, prevista en el art. 30.2 CE, que permitiera la plena aplicabilidad y eficacia del derecho a la objeción de conciencia por él alegada.

El TC consideró que, en cuanto al fondo del asunto, una cuestión debatida que condicionaba la decisión sobre el otorgamiento del amparo era el reconocimiento en nuestro ordenamiento jurídico de la objeción de conciencia como derecho constitucional. El TC dio a esta cuestión respuesta afirmativa y en su fundamentación aludió al derecho comparado, en particular a que en la Ley Fundamental de Bonn el derecho a la objeción de conciencia se reconoce en el mismo artículo que la libertad de conciencia (FJ 6) ${ }^{18}$.

18 En la STC 124/1984, de 18 de diciembre, el derecho comparado fue canon desde el que enjuiciar las causas de admisión del recurso de revisión penal, regulado por normativa preconstitucional. El recurso de amparo giraba en torno al papel que desempeñan el Ministerio de Justicia y el Ministerio Fiscal en la regulación, preconstitucional, del recurso de revisión, considerada a la luz de la Constitución de 1978, y suscita expresamente la cuestión de su compatibilidad con las exigencias del art. $24 \mathrm{CE}$. El TC desestimó el amparo. Aunque su argumentación es principalmente de derecho interno, se acude al derecho comparado, es verdad que, sin proporcionar detalles, dos veces, que se incardinan de manera sustancial en el hilo argumental de la Sentencia. La primera para señalar que las causas de admisión del recurso son homologables con las existentes en el derecho comparado; la segunda para explicar que no hay un único régimen posible de este recurso desde el punto de vista constitucional, que el legislador tiene margen para su configuración. Un fragmento de esta última cita será empleado en STC 123/2004, de 13 de julio, para fundamentar la existencia del trámite de autorización previsto en el art. 957 LECrim (en esta última, también en un voto particular). Siempre sin fundamentar detalladamente la cita y realizándola con carácter genérico.

En la STC 196/1995, de 19 de diciembre, en un voto particular el entonces magistrado Jiménez de Parga propone una forma de agotamiento de la vía judicial previa similar a la alemana.

En la STC 117/1998, de 2 de junio, se recibe el criterio del Tribunal Constitucional federal alemán que circunscribe a las personas físicas la exigibilidad constitucional del beneficio de justicia gratuita. Se trataba de un recurso de amparo que sostenía que un Auto de determinado Juzgado, que denegó a la sociedad demandante el derecho a la asistencia jurídica gratuita que había solicitado para promover un procedimiento de suspensión de pagos, por tratarse de una persona jurídica "con ánimo de lucro" no encuadrable en los supuestos del art. 2.c) de la Ley 1/1996, de Asistencia Jurídica 


\subsubsection{STC 136/1999, de 20 de julio: derecho comparado como criterio para valorar el propio derecho penal antiterrorista}

En lo que aquí nos interesa, el objeto de esta Sentencia fue la Sentencia del Tribunal Supremo por la que se había condenado a los veintitrés demandantes de amparo, todos ellos miembros de la Mesa Nacional de la asociación política Herri Batasuna, como autores de un delito de colaboración con banda armada a la pena de siete años de prisión mayor y multa de quinientas mil pesetas, con otras accesorias. La pena se había impuesto por entender que habían realizado «un acto de colaboración con ETA, concretado en la decisión adoptada por los componentes de la Mesa Nacional de HB, en su reunión de 5 de febrero de 1996, de ceder a una organización terrorista los espacios electorales gratuitos que como formación política le correspondían, asumiendo de esta forma su contenido» ${ }^{19}$.

No quedó rastro en los antecedentes de Hecho de invocación alguna de derecho comparado.

El caso dio lugar a un voto particular concurrente (magistrado Viver PiSunyer) y a tres votos particulares discrepantes (magistrados Mendizábal Allende, Jiménez de Parga y Cabrera y Conde Martín de Hijas).

Del amplio elenco de derechos fundamentales invocados por los recurrentes, el TC consideró el derecho a la legalidad penal había sido vulnerado (art. 25.1 CE) y, en consecuencia, otorgó el amparo.

En la fundamentación jurídica encontramos uso del derecho comparado en dos lugares. Primero, para justificar la existencia en nuestro derecho, en materia de legislación antiterrorista, de un tipo muy poco específico de colaboración o apoyo a grupos terroristas, condicionado por la necesidad de no dejar fuera, dentro de lo posible, ninguna forma o variedad de respaldo

Gratuita, había vulnerado el derecho a la tutela judicial efectiva sin indefensión del art. 24.1 CE y el derecho a la igualdad jurídica del art. $14 \mathrm{CE}$.

El TC desestimó el amparo. Como presupuesto para dilucidar si había vulneración de los arts. 14 y $24 \mathrm{CE}$, se planteó los límites de la libertad de configuración del legislador al regular el derecho a la asistencia jurídica gratuita. Para contestar a esta cuestión se atiende a jurisprudencia anterior del TC español y al Tribunal Constitucional Alemán en Sentencia de 3 de julio de 1973 al enjuiciar la regulación contenida en el art. 114.4 de la Ordenanza Procesal Civil (actual art. 116 ZPO). El derecho comparado se integra de manera muy relevante en la argumentación de la Sentencia. La Sentencia tuvo un voto particular discrepante que no se refirió a la cuestión del derecho comparado.

19 El FJ 1 resume los hechos declarados probados objeto de condena. 
individual o social al fenómeno terrorista. ${ }^{20}$ Segundo, al analizar la proporcionalidad del tipo penal del art. 174 bis a) del Código Penal, de 1973, es decir, «si resulta proporcionada una figura delictiva que condena las conductas descritas a penas de un mínimo de seis años y un día de prisión.» Aquí el TC, para añadir fundamento a su argumentación, que considera que el tipo no supera el requisito de la proporcionalidad en sentido estricto, aduce la regulación existente en otros países: Alemania, Austria, Reino Unido e Italia (FJ 29).

Tal vez desde una perspectiva científica estricta, como dice De Vergottini, parece evidente que en casos como este «la referencia a regímenes normativos extranjeros puede sin duda ser útil a fines cognoscitivos, pero en sí misma no tiene que ver con la comparación.» Pero no se debe minimizar la importancia de la invocación. Pienso que debió de tener un gran peso en el ánimo del Tribunal cómo sería vista esta Sentencia por el resto de Europa y por el TEDH. Por eso, aunque la forma literal de la redacción de la Sentencia hace pensar en un argumento «a mayor abundamiento», no integrado en la ratio decidendi, se trata de un argumento de gran relevancia ${ }^{21}$.

La Sentencia dio lugar a cuatro votos particulares ${ }^{22}$, uno de ellos concurrente y tres discrepantes, pero en ninguno de ellos se hacen observaciones de derecho comparado o del empleo del mismo por la Sentencia ${ }^{23}$.

20 FJ 30.

21 Esta Sentencia envió al legislador el mensaje de que redujera la duración de las penas, pero el legislador no lo acogió. En cambio, probablemente la Sentencia descorazonó al Gobierno respecto del empleo de la vía penal para luchar contra el brazo político de ETA y, de esta manera, acabó generando la peculiar Ley de Partidos de 2002, como vía adicional a la penal pero que, de hecho, desplazó a esta última (Tenorio Sánchez, 2010: 304).

22 Un voto particular concurrente del magistrado Viver Pi-Sunyer y tres votos particulares discrepantes de los magistrados Mendizábal Allende, Jiménez de Parga y Conde Martín de Hijas.

23 En la STC 57/2004, de 19 de abril de 2004, en un voto particular discrepante, el magistrado Rodríguez-Zapata invocó el derecho comparado para implantar entre nosotros un régimen análogo de la publicidad en los juicios que evite los juicios paralelos. El magistrado se refería al derecho de Reino Unido y Estados Unidos. A ello se añadía la invocación de jurisprudencia constitucional alemana y la ley austríaca, para terminar refiriéndose a la canadiense. 


\subsubsection{STC 237/2005, de 26 de septiembre de 2005: empleo del derecho comparado para interpretar conforme al Constitución las previsiones legales de los supuestos de justicia universal}

En el caso resuelto por esta Sentencia se plantearon diversas demandas de amparo dirigidas contra determinada Sentencia del Tribunal Supremo que había estimado parcialmente el recurso de casación interpuesto contra determinado Auto del Pleno de la Sala de lo Penal la Audiencia Nacional, así como contra esta última resolución. El núcleo de la controversia suscitada se proyectaba sobre la interpretación restrictiva que, si bien en virtud de argumentos diversos, ambos órganos judiciales habían efectuado sobre el art. 23.4 de la Ley Orgánica del Poder Judicial (LOPJ) y el criterio de competencia jurisdiccional penal allí establecido, referible al principio de la denominada jurisdicción universal, con la consecuencia de negar, en todo o en parte, la competencia de los tribunales españoles para la persecución y el enjuiciamiento de los hechos objeto de las denuncias que habían dado lugar al procedimiento, hechos calificados en las citadas denuncias como genocidio, terrorismo y torturas, cometidos en Guatemala a lo largo de los años setenta y ochenta. Las tres demandas de amparo denunciaban que las resoluciones impugnadas habían procedido a una interpretación infundadamente restrictiva y contra legem del citado precepto.

El TC otorga el amparo y en su argumentación va a terciar en una polémica de derecho comparado que se había producido en el Tribunal Supremo. Este, en apoyo de su presupuesto de partida, a saber, que en la costumbre internacional se ha venido restringiendo el alcance del principio de justicia universal, invocaba determinadas resoluciones jurisprudenciales de tribunales de terceros Estados o internacionales; así, citaba en particular diversas resoluciones del Tribunal Supremo federal alemán y la decisión de la Corte de Casación belga sobre el Caso Sharon.

El TC afirma que resulta harto discutible que tal sea la regla en la costumbre internacional y ello, en particular, por cuanto la selección de referencias jurisprudenciales efectuada por el Tribunal Supremo en apoyo de dicha tesis no abona tal conclusión, sino, más bien, la contraria. A ello añade el TC referencias de derecho comparado no citadas por el Tribunal Supremo. En suma, sin entrar a polemizar acerca de si estas observaciones de derecho comparado se integran o no en sentido estricto en la ratio decidendi, es evidente que son fundamentales en la Sentencia. 


\section{STC 12/2008, DE 29 DE ENERO, E IGUALDAD DE SEXOS EN LAS LISTAS ELECTORALES. EL TRIBUNAL CONSTITUCIONAL SE PLANTEA EL EMPLEO DEL DERECHO COMPARADO Y CONCLUYE QUE EL ÚNICO CANON DE SUS DECISIONES HA DE SER LA CONSTITUCIÓN ESPAÑOLA}

1. Consideramos que esta Sentencia debería considerarse un hito en el análisis de la evolución de la consideración del derecho comparado por parte del TC. Antes de ella, el TC había hecho uso del derecho comparado y lo había reflejado en algunas decisiones. Como hemos visto, ese reflejo en las decisiones no llegaba a tener entidad de un estudio riguroso del derecho comparado ni tampoco era normalmente esencial en la motivación, es decir, no está claro en ningún caso que estemos, en rigor, ante la ratio decidendi de una sentencia.

Si bien no cabe minimizar la importancia en un doble sentido. Por una parte, porque lo que se refleja en las sentencias viene a ser la punta del iceberg: el derecho comparado tiene mucho más peso en las sentencias del TC del que aparece explícitamente reconocido. Por otra parte, en el propio tenor literal de las sentencias, en ocasiones se percibe que la invocación del derecho comparado, sin entrar en la polémica de si puede considerarse o no ratio decidendi, tiene una gran importancia en el hilo argumental de la Sentencia.

Pero en todo caso nunca se refleja debate, duda o discusión sobre la aplicación del derecho comparado como fuente o como argumento.

En cambio, en la STC 12/2008, aunque propiamente no se reflejara un debate en que las diferentes posturas se consignaran, se percibe que el TC tuvo que plantearse si se alineaba con el Tribunal Constitucional italiano y con el Consejo Constitucional francés o no. El TC resuelve la cuestión argumentando, por una parte, que el derecho comparado no es canon de sus resoluciones. Esto es una declaración cuya importancia hay que destacar. No obstante, se diría que el TC no se queda satisfecho en el presente caso con esa respuesta y por eso, a mayor abundamiento, señala que la CE, por lo que se refiere a la regulación de la igualdad, es distinta a la italiana y a la francesa con anterioridad a los pronunciamientos de sus órganos de justicia constitucional y subsiguientes reformas constitucionales. Con ello, el TC señala una directriz metodológica para la aplicación del derecho comparado: es preciso, para la aplicación del mismo, la analogía de la regulación constitucional.

2. La STC 12/2008, de 29 de enero, resolvió una cuestión de inconstitucionalidad y un recurso de inconstitucionalidad planteado contra el art. 44 bis de la LO 5/1985, del régimen electoral general (LOREG), introducido por la disposición adicional segunda de la LO 3/2007, para la igualdad efectiva de mujeres y hombres (LOIMH). 
El art. 44 bis LOREG estableció, en síntesis, que las candidaturas que se presentaran para las diferentes elecciones que se celebraran en España debían tener una composición equilibrada de mujeres y hombres, de forma que en el conjunto de la lista los candidatos de cada uno de los sexos supusieran como mínimo el $40 \%$.

Básicamente se reprochaba la vulneración de los arts. 14 (principio de igualdad) y 23 (derecho de sufragio) CE.

3. En los antecedentes consta que en este caso las partes plantearon un consistente debate de derecho comparado.

El órgano judicial que planteó la cuestión de inconstitucionalidad, sin perjuicio de exponer los argumentos de derecho interno, reseñaba que tanto la Corte Constitucional italiana como el Consejo Constitucional francés habían apreciado discriminación en regulaciones análogas a la ahora controvertida.

También se recogen en los antecedentes las razones que expone la Abogacía del Estado en virtud de las cuales concluye que la doctrina constitucional de derecho comparado que se alega de contrario no resulta trasladable a nuestro ordenamiento jurídico. Añadía la Abogacía del Estado que en las reformas constitucionales llevadas a efecto en Europa concurren elementos que no se dan en España. Estos argumentos serán asumidos como propios por el TC.

También en el ámbito del recurso de inconstitucionalidad fue traído a colación el derecho comparado. En este sentido, los recurrentes dan cuenta del contenido de la Sentencia de la Corte Constitucional de Italia de 6 de septiembre de 1995, donde se afirma que la absoluta igualdad de sexos impide que la pertenencia a uno de ellos pueda ser asumida como requisito de elegibilidad. El repaso del panorama de derecho comparado se completa en el recurso de inconstitucionalidad con una referencia a la evolución que ha tenido lugar en Francia y Bélgica.

4. Nuestro TC desestimó la cuestión y el recurso basándose en razones de derecho interno, pero abordó el asunto del empleo del derecho comparado. A este respecto, contestó que el «único canon de sus resoluciones es la Constitución española». Inciden en la materia dos párrafos, que contienen diferentes argumentos.

En primer lugar, parece negar el carácter vinculante del derecho comparado, aunque con un circunloquio abigarrado y farragoso que niega de alguna manera valor los tratados internacionales; concretamente dirá, en el FJ 2:

Pese a la relevancia que tales argumentos tienen en los discursos sostenidos por las distintas partes, hay que recordar que, según nuestra doctrina, «los Tratados internacionales no constituyen canon para el enjuiciamiento de la adecuación a 
la Constitución de normas dotadas de rango legal [SSTC 49/1988, de 22 de marzo, FJ 14; 28/1991, de 14 de febrero, FJ 5; 254/1993, de 20 de julio, FJ 5] (STC 235/2000, de 5 de octubre, FJ 11), lo que no puede ser óbice para subrayar la importancia que reviste la remisión constitucional (art. 10.2 CE) a determinados instrumentos de derecho internacional como criterio interpretativo de los derechos fundamentales [...]

En segundo lugar, no obstante, va a explicar la razón por la que no va a proceder como los órganos de justicia constitucional francés e italiano, concretamente, hace referencia al diferente tenor literal de las correspondientes constituciones; y aquí sí va a negar el carácter vinculante del derecho comparado: "[...] los avatares de las jurisprudencias italiana y francesa a que también se refieren las partes se explican justamente a partir de una diferencia fundamental entre aquellos ordenamientos y el nuestro, [...] la Constitución española, (que) constituye, obviamente, nuestro único canon de constitucionali$d a d »{ }^{24}$.

5. Se trataba de un caso difícil, que registró un voto particular (magistrado Rodríguez-Zapata) que, sin entrar a argumentar con detalle, llamaba la atención sobre el hecho de que en importantes países europeos las reformas legales de este tipo habían sido precedidas de reformas constitucionales.

En resumen, ante la invocación del derecho comparado por las partes, el TC, con la discrepancia de un solo magistrado, niega la condición de canon de sus decisiones al constitucionalismo comparado. Lo que no le basta para resolver el asunto, sino que añade razones concretas para no seguirlo en el presente supuesto.

\section{RESOLUCIONES DEL TRIBUNAL CONSTITUCIONAL RELATIVAS AL DERECHO COMPARADO POSTERIORES A LA STC 12/2008, DE 29 DE ENERO}

\subsection{STC 198/2012, de 6 de noviembre: invocación de la tendencia del derecho comparado para fundamentar la constitucionalidad de la ley que estableció el matrimonio homosexual}

1. Recurso de inconstitucionalidad interpuesto contra la totalidad de la Ley 13/2005. El núcleo del recurso lo constituía el primer apartado del artículo único de la Ley, que añade un segundo párrafo al art. 44 del Código Civil, en virtud del cual «el matrimonio tendrá los mismos requisitos y efectos cuando ambos contrayentes sean del mismo o de diferente sexo».

24 FJ 2 (la cursiva es nuestra). 
2. En los antecedentes de Hecho se invocó el derecho comparado, aunque valorándolo una y otra parte de manera contrapuesta.

3. Se trataba de un caso difícil, en el que se redactaron cuatro votos particulares importantes. En tres de ellos se habla del derecho comparado, pero en realidad no hubo mucho debate sobre el empleo del derecho comparado, lo que no debe sorprender, pues en realidad no había discusión sobre si este se debía tener en cuenta o no, sino sobre cuál era su significado. O bien sobre si se aplicaba el derecho comparado del momento en que se aprobó la Ley o lo que la ponencia decidió que era la tendencia evolutiva del derecho comparado. Sorprende que no se recordara la afirmación tajante de la STC 12/2008 que excluía el derecho comparado como canon de las decisiones del TC.

4. El TC desestimó el recurso de inconstitucionalidad y en la fundamentación jurídica hizo un uso abundante del derecho comparado. En primer lugar, se acude a él como un elemento más integrante de lo que la Sentencia llama «interpretación evolutiva» y cultura jurídica, que parecen entroncar con la interpretación en relación con la realidad social a la que ha de ser aplicada la CE y que resultan ser decisivos para soslayar su aplicación literal ${ }^{25}$. En segundo lugar, se invoca la evolución de la institución en el derecho comparado para concretar la «imagen» actual del matrimonio ${ }^{26}$. Tercero, tal vez consciente de que el número de países era insignificante para enervar el tenor literal de la CE, el TC subraya la importancia de la evolución para concluir que la imagen del matrimonio en el derecho comparado es "plural $»^{27}$ como una conclusión del análisis del derecho comparado $^{28}$.

5. Resulta claro que la Sentencia se basa, no en el derecho comparado, sino en una interpretación discutible de este en lo que ella considera tendencia en la evolución del mismo. Sin embargo, esto no va a ser señalado con claridad por los magistrados discrepantes, que orientan su crítica a la opinión de la mayoría por otros cauces distintos del que aquí nos ocupa.

25 FJ 9: «[...] la Constitución es un «árbol vivo» —en expresión de la sentencia Privy Council, Edwards c. Attorney General for Canada de 1930 retomada por la Corte Suprema de Canadá en la sentencia de 9 de diciembre de 2004 sobre el matrimonio entre personas del mismo sexo- que, a través de una interpretación evolutiva, se acomoda a las realidades de la vida moderna como medio para asegurar su propia relevancia y legitimidad [...]».

26 FJ 9.

27 Idem.

28 FJ 11 
En efecto, el voto particular del magistrado Rodríguez Arribas resume primero el método de la Sentencia (recurso a la cambiante cultura jurídica, que incluiría el derecho comparado) y lo discute sin precisar la confusión que se hace en la Sentencia entre «derecho comparado» y tendencia de este.

Esto conduce al magistrado a incluir en el objeto de su discrepancia el derecho comparado (que se considera conjuntamente con el derecho internacional), aunque sin traer a colación la jurisprudencia anterior del TC que minimizaba su peso (STC 12/2008, de 29 de enero).

En el voto particular discrepante del magistrado Ollero Tassara sí se subraya que se sustituye el tenor de la CE por una interpretación evolutiva, pero no se señala la diferencia entre esta y el derecho comparado en sentido propio, por lo que se acaba criticando el supuesto uso que hace la Sentencia del derecho comparado, de nuevo sin traer a colación la jurisprudencia anterior del TC que minimizaba su peso (STC 12/2008, de 29 de enero). Lo que se postula es que se puede utilizar en caso de duda sobre lo que dice el derecho nacional, pero no erigirlo en un derecho supraconstitucional.

En el voto particular del magistrado González-Rivas se parte de que es legítimo el recurso al derecho comparado, pero este último se interpreta de una manera muy distinta a la de la Sentencia y similar a la de los recurrentes. En este sentido, se parte de que el matrimonio del derecho comparado es el anterior a la reforma, entroncando con un planteamiento iusnaturalista; a lo que se añade que el derecho comparado de lo que ofrece ejemplo es de enfocar las uniones de personas del mismo sexo no igualándolas al matrimonio, sino como uniones civiles distintas del matrimonio.

\subsection{ATC $180 / 2013$, de 17 de septiembre: derecho comparado para fundamentar la posibilidad de que los magistrados del Tribunal Constitucional estén vinculados a partidos políticos}

Resuelve la recusación presentada por la Generalidad y el Parlamento de Cataluña contra el magistrado del TC Pérez de los Cobos, a la sazón presidente del TC, con referencia a varios procesos constitucionales. Ambas recusaciones se sustentaban en la conjunción de los siguientes hechos: primero, la afiliación del magistrado Pérez de los Cobos a un partido político durante un lapso de tiempo parcialmente coincidente con su condición de magistrado del TC; segundo, que no hubiera puesto en conocimiento de la Comisión de Nombramientos del Senado el dato de su afiliación política; tercero, que antes de su nombramiento hubiese colaborado con una fundación de estudios vinculada al Partido Popular mediante intervenciones relacionadas en algunos casos con cuestiones sujetas al conocimiento del TC; y, 
por último, que hubiera publicado un libro de aforismos, algunos de los cuales denotarían animadversión hacia Cataluña, los catalanes y el nacionalismo catalán.

Resultó ser un caso difícil que levantó gran polvareda en los medios de comunicación y en el que se formularon dos votos particulares.

El TC inadmitió las recusaciones. Tras exponer las razones claras de derecho interno, reproduciendo el art. 159.4 CE, que diferencia el régimen de los magistrados constitucionales y el de los integrantes del poder judicial, se añade una contundente referencia al derecho comparado, que incluye a Alemania, Italia, Francia y Portugal. Aquí el derecho comparado era manifiestamente innecesario como ratio decidendi, pero no cabe duda de que añade de alguna manera fundamentación a la decisión.

Los votos particulares no discutieron el empleo del derecho comparado como argumento. Uno de ellos (el del magistrado Ortega Álvarez) se refirió a la insuficiencia de la interpretación literal de la CE defendiendo la interpretación «evolutiva» de la misma. Un intento de obviar el tenor literal de la Constitución.

\subsection{STC 199/2013, de 5 de diciembre: invocación del derecho comparado} para delimitar la validez de una prueba relacionada con el ADN

La STC 199/2013, de 5 de diciembre, resolvió un recurso de amparo contra una condena de la Audiencia Nacional, confirmada por el Tribunal Supremo, al autor de un delito de daños terroristas a la pena de seis años de prisión y privación del derecho de sufragio por el mismo tiempo.

El recurrente en amparo denunciaba que se había vulnerado, entre otros derechos, su intimidad, porque se había obtenido su perfil de ADN analizando un esputo suyo escupido en la celda mientras estaba detenido, sin que tal actuación hubiera sido autorizada judicialmente.

El TC consideró que la obtención del perfil de ADN del esputo no vulneraba el derecho a la intimidad y para argumentar trajo a colación el derecho comparado. En este sentido, subrayó que el perfil de ADN se había obtenido a partir de marcadores que no revelaban las características genéticas del detenido, esto es, a efectos meramente identificativos, por lo que tal proceder no vulneraba los derechos del recurrente, y para apoyar esta aseveración invoca una Sentencia del Tribunal Supremo de Estados Unidos. Añadió que la legitimidad de la obtención de esta prueba limitándose a las regiones de ADN no codificante era acorde con la normativa internacional y citó un tratado de cooperación en el ámbito de la lucha contra el terrorismo. 


\subsection{STC de Pleno 92/2014, de 10 de junio: Sentencias del Tribunal Constitucional que aplican su doctrina}

Con la STC 92/2014, de 10 junio, el Pleno del TC resolvió una cuestión interna de inconstitucionalidad en relación con el art. 174.1 de la Ley General de la Seguridad Social, Real Decreto Legislativo 1/1994, de 20 julio, en la redacción dada por la Ley 50/1998, de 30 diciembre, de Medidas Fiscales, Administrativas y del Orden Social. La duda se refería a si el precepto cuestionado, en la medida en que solo reconocía a la pensión de viudedad al cónyuge supérstite, podía suponer una vulneración del art. $14 \mathrm{CE}$, al implicar una desigualdad de trato de las parejas homosexuales respecto de las parejas heterosexuales, y por tanto una discriminación por razón de la orientación sexual, proscrita en el art. 14, segundo inciso CE, ya que al no existir, en el momento en que se le denegó la pensión al recurrente en amparo del que traía causa la cuestión, posibilidad legal de contraer matrimonio entre personas del mismo sexo, las parejas estables homosexuales nunca podían encontrarse en la situación establecida por el art. 174.1 de la Ley General de la Seguridad Social, con la consiguiente imposibilidad de acceder a la petición de viudedad.

El Pleno desestimó la cuestión de inconstitucionalidad. Argumentó para ello conjugando varias ideas o datos, entre los que destacamos tres. Primero, de acuerdo con la STC 198/2012, de 6 noviembre, es constitucional que el legislador admita el matrimonio entre personas del mismo sexo, pero esto último no es constitucionalmente exigido. Segundo, el legislador tiene un amplio margen de apreciación y configuración del régimen de prestaciones económicas de la seguridad social, como dijo la STC 41/2013. Tercero, la extensión de la pensión de viudedad a quienes convivían de forma estable estaba «lejos de ser la pauta en la legislación internacional y en el derecho comparado en aquel momento [STC se 184/1990 (FJ 5)]». Es decir, incorpora a su argumentación el derecho comparado del momento en que se promulgó la ley General de la Seguridad Social.

La STC 92/2014, de 10 junio, por lo demás, incluye un voto particular del magistrado Ortega Álvarez al que se adhieren otros tres magistrados. Un voto particular discrepante que sostiene que se debería haber estimado la cuestión, pero que ni invoca el derecho comparado ni discute la invocación que hace del mismo la sentencia de la mayoría.

Con posterioridad a la STC 92/2014, el TC dictó 5 sentencias (SSTC) que aplicaban la doctrina sentada en la misma a otros tantos recursos de amparo. Son las SSTC 93/2014, de 12 de junio; 98/2014, de 23 de junio; 115/2014, de 8 de julio; 116/2014, de 8 de julio, y 124/2014, de 21 de julio. Todas ellas desestiman el amparo correspondiente, reproducen la referencia al 
derecho comparado del momento en que se promulgó la Ley General de la Seguridad Social e incluyen un voto particular discrepante suscrito por cuatro magistrados que se remite al voto particular de la STC 92/2014.

\section{CONCLUSIONES Y CONSIDERACIONES FINALES}

Hemos intentado seleccionar en la jurisprudencia del TC aquellos casos en que el derecho comparado no es simplemente mencionado, sino que se integra en la ratio decidendi de la sentencia. En este sentido, es menester indicar que, tal y como señala De Vergottini, en rigor nuestro TC nunca ha utilizado el derecho comparado como ratio decidendi. Sin embargo, pensamos que en muchos casos ha tenido relevancia la consideración de dicho derecho y, además, se refleja en los FFJJ. Por otra parte, hemos procurado incluir las ocasiones en que la utilización del derecho comparado no aparece en la fundamentación jurídica, pero sí en los antecedentes de hecho o en votos particulares. Después de todo, su presencia en los antecedentes indica que las partes lo consideran argumentable y su aparición en un voto particular indica que el magistrado o magistrados correspondientes lo consideran válido como ratio decidendi de un desenlace distinto al alcanzado.

En realidad, si consideráramos que solamente se emplea el derecho comparado cuando este no solo se cita, sino que media la realización previa de un estudio verificable y que además se inserta plenamente como ratio decidendi en una sentencia, prácticamente no podríamos encontrar casos de utilización del derecho comparado ni en España ni en la mayoría de los países. Seguramente habría que buscar los ejemplos de Sudáfrica y algunos países del Common Law, o el Tribunal Constitucional de Hungría.

Entre nosotros, la forma de elaboración de las sentencias que tiene el TC, con larga motivación y votos particulares, hubiera permitido que tuviera lugar en nuestro TC un debate sobre la utilización del derecho comparado que se hubiera traslucido en las sentencias y votos particulares. No es el caso de Italia, donde las sentencias son muy sucintamente motivadas y no caben votos particulares, lo que difícilmente permite que, en caso de que haya debate entre los magistrados sobre la utilización del derecho comparado, este se plasme por escrito en la sentencia.

El TC español considera el derecho constitucional comparado siempre que se alega ante él e incluso, en ocasiones, por propia iniciativa. No se puede decir, en rigor, que lo haga de oficio, ya que para el derecho comparado, entendemos que, en principio, no rige el principio iura novit curia.

$\mathrm{Al}$ derecho comparado le es aplicable la jurisprudencia de nuestro TC, según la cual el derecho extranjero tiene la consideración de mero hecho y, en 
consecuencia, debe ser probado por quien lo alega. Ahora bien, esto no debe hacernos pensar que sean idénticos los casos en que el TC habla de derecho extranjero y los casos en que habla de derecho comparado. Los primeros ${ }^{29}$ son casos en los que se somete a la consideración del TC la necesidad de aplicar una norma extranjera de detalle, muy concreta, con una razón singular. En cambio, los casos en que se hablará de derecho comparado son asuntos en que se vuelve la mirada al derecho extranjero para indagar si existe una regulación o institución generalizada de la que se desprenda un principio o regla aplicable también en nuestro derecho.

Por otra parte, no es unánime la opinión que la utilización del derecho comparado merece a los diferentes magistrados. En general, los magistrados de origen de la carrera judicial, habituados a aplicar el ordenamiento positivo español, son más reacios a las consideraciones de derecho comparado que los magistrados de origen universitario. Hemos visto importantes citas de derecho comparado en votos particulares de dos magistrados de origen universitario: Jiménez de Parga (Universidad Complutense de Madrid), Rodríguez-Zapata (UNED) y Ollero Tassara (Universidad Juan Carlos I).

El derecho comparado en el TC tiene un considerable peso especialmente en los casos difíciles. Entendemos por difíciles aquellos casos que dividen de manera aguda al TC y a la opinión pública y sobre los que se cierne la sospecha de que la actuación de los magistrados queda condicionada por sus prejuicios ideológicos o creencias. Son los casos difíciles respecto de los cuales la tradición americana ha formulado el aforismo hard cases make bad law.

Cuando nuestro TC invoca el derecho comparado, en realidad lo que suele hacer es emplear como argumento de autoridad la regulación jurídica o las sentencias de los órganos de justicia constitucional de Estados de derecho o democracias de prestigio con un sistema jurídico próximo al nuestro. Es obvio que tiene sentido que nuestro TC intente avalar sus decisiones citando las decisiones de otros Estados europeos que son democracias consolidadas, y no con el criterio de otros países más lejanos histórica, cultural y jurídicamente y con menor tradición democrática. Además, concretamente, dentro de los países europeos, el derecho al que más se vuelve la mirada es el de Italia y el de Alemania, lo que se explica porque estos países tienen las dos Constituciones que más influencia han tenido probablemente en la redacción de la Constitución española vigente $y$, además, presentan un sistema de justicia

29 SSTC 10/2000, de 17 de enero; 155/2001, de 2 de julio; 33/2002, de 11 de febrero; 29/2004, de 4 de marzo; 34/2004, de 8 de marzo; 172/2004, de 18 de octubre; 181/2004, de 2 de noviembre; 263/2005, de 24 de octubre. AATC 395/2003, de 11 de diciembre; 422/2004, 4 de noviembre; 523/2004, 20 de diciembre. 
constitucional considerablemente similar. Junto a ello, como hemos visto, se encuentra alguna invocación del criterio del Tribunal Supremo de Estados Unidos.

Intentando señalar una evolución en la utilización del derecho comparado por parte del Tribunal constitucional cabría distinguir tres etapas:

a) Utilización del derecho comparado que se refleja escasamente en la fundamentación jurídica, sin debatir si es fuente o no, pero utilizándolo en casos dificiles como un argumento de peso conectado de alguna manera con la ratio decidendi, aunque sin constituir nunca su núcleo. Este período sería desde los orígenes hasta la STC 12/2008, de 29 de enero. Es sabido que en los primeros tiempos del TC nuestros magistrados se inspiraron en los ejemplos alemán e italiano, pero de ello no ha quedado constancia en los textos de las sentencias. En este largo período destaca, desde el punto de vista que aquí nos interesa, la STC 136/1999, de 20 de julio, sin duda una de las cuatro sentencias más importantes en cuanto a la utilización del derecho comparado, que tuvo gran influencia en la evolución del derecho penal antiterrorista e indirectamente en el derecho de partidos.

b) En la STC 12/2008, de 29 de enero, el TC se encuentra ante una invocación de resoluciones de órganos de justicia constitucional de Italia y de Francia de mucho peso y parece que debió plantearse en las deliberaciones hasta qué punto el derecho comparado podía considerarse fuente de las resoluciones del TC. Como hemos visto, el TC dice explícitamente que el único canon de sus resoluciones es la CE, y descarta así como canon o fuente el derecho comparado.

c) Con posterioridad a esta resolución, parece que durante algún período de tiempo el TC dejó de invocar el derecho comparado, pero pronto volvió a hacerlo, con las mismas características que en el primer período y sin plantearse una revisión de su doctrina sentada en la STC 12/2008, de 29 de enero. Es más, como hemos visto, la supuesta tendencia del derecho comparado juega un papel muy importante para decidir acerca de la constitucionalidad del matrimonio homosexual.

En suma, en la situación actual, consideramos que el derecho comparado es un argumento de peso que se puede utilizar y se utiliza ante nuestro TC. Y que cuando se invoque, el TC contestará al argumento planteado.

Además, hay que tener en cuenta una característica del valor de las sentencias del TC que puede incidir en las invocaciones que hace nuestro TC del derecho comparado en los FFJJ de sus sentencias. Nos referimos a lo dispuesto por el art. 5 de la LOPJ: 
Art. 5.1. La Constitución es la norma suprema del ordenamiento jurídico, y vincula a todos los Jueces y Tribunales, quienes interpretarán y aplicarán las leyes y los reglamentos según los preceptos y principios constitucionales, conforme a la interpretación de los mismos que resulte de las resoluciones dictadas por el Tribunal Constitucional en todo tipo de procesos.

Como consecuencia de este precepto debemos entender que las sentencias del TC no solamente son vinculantes en cuanto a su fallo, sino también en lo que se viene llamando su doctrina o proclamaciones de reglas, principios o criterios, que suele hacer en sus FFJJ para fundamentar sus resoluciones, exponiéndolos en uno o varios FFJJ, con anterioridad a su aplicación al caso concreto. El propio TC se considera vinculado, en principio, por esta doctrina que sienta en sus sentencias. Pues bien, en esas proclamaciones del TC pueden incluirse alusiones al derecho comparado.

Una cuestión que debe plantearse en relación con la utilización del derecho comparado es la de hasta qué punto, en caso de ser utilizado, debe reflejarse este hecho en las resoluciones judiciales. Hemos visto que nuestro TC, en nuestra opinión, lo usa más de lo que lo se refleja en sus resoluciones. Además, cuando lo refleja, normalmente alude a él de una forma muy vaga. ¿No aportaría más seguridad jurídica y sería más conforme al Estado de derecho que se explicitara con mayor claridad el derecho comparado que se invoca? A primera vista se siente uno tentado a recomendar que se haga así. Sin embargo, este impulso debe atemperarse con la consideración de que, en ocasiones, resulta difícil una consideración pormenorizada, con fuentes directas, del derecho comparado. Tal vez el conocimiento del mismo se obtenga a través de un manual o de un artículo científico en una revista, y se confirme de manera más o menos informal en una conversación. Nuestros tribunales constitucionales están muy sobrecargados de trabajo y no conviene distraer sus energías obligándolos a proporcionar estudios de derecho comparado impecables. Por lo tanto, estimamos que sería conveniente especificar, en la medida de lo posible, más de lo que se hace, las citas de derecho comparado, en aquellos casos en que se tenga disponible. En suma, sin que podamos considerarlo plenamente exigible, conviene hacer la referencia. Conviene, dicho de otra manera, que asome a la superficie más parte del iceberg.

\section{Bibliografía}

Carpentier E. (2009). La utilización de la jurisprudencia constitucional extranjera por el Consejo Constitucional francés. Memoria del X Congreso iberoamericano de derecho constitucional, vol. 2, (pp. 475 y ss.). Lima: Idemsa. 
Mertens de Wilmars, J. (1991). Le droit comparé dans la jurisprudente de la Court de Justicie des Communautés Européennes. Journal des Tribunaux, 37 y ss.

Tenorio Sánchez, P. (2010). Constitución, derechos fundamentales y seguridad. Panorama comparativo. Madrid: Civitas Thomson Reuters.

- (2013). El matrimonio, derecho constitucional e institución de derecho civil. En Estudios sobre derechos fundamentales. Desarrollos recientes (pp. 97 y ss.). Regensburg: Universität Regensburg.

Torres del Moral, A. (2010). Principios de derecho constitucional español. Tomo I: Sistema de fuentes. Sistema de los derechos. Madrid: Universidad Complutense de Madrid.

Vergottini, G. de. (2010). Más allá del diálogo entre tribunales. Comparación y relación entre jurisdicciones. Madrid: Civitas Thomson Reuters. 
